\title{
(6) OPEN ACCESS \\ Going home after infant cardiac surgery: a UK qualitative study
}

Jenifer Tregay, ${ }_{1}^{1}$ Jo Wray, ${ }_{1}$ Sonya Crowe, ${ }^{2}$ Rachel Knowles, ${ }^{3}$ Piers Daubeney, ${ }_{1}^{4,5}$ Rodney Franklin, ${ }^{4}$ David Barron, ${ }^{6}$ Sally Hull, ${ }^{7}$ Nick Barnes, ${ }^{8}$ Catherine Bull, ${ }_{1}$ Katherine L Brown ${ }^{1}$

${ }^{1}$ Cardiac Unit, Great Ormond Street Hospital NHS Foundation Trust, London UK

${ }^{2}$ Clinical Operational Research Unit, University College London, London, UK ${ }^{3}$ Population, Policy and Practice Programme, UCL Institute of Child Health, London UK

${ }^{4}$ Paediatric Cardiac Unit, Royal Brompton and Harefield Hospitals NHS Trust, London, UK

${ }^{5}$ Royal National Heart and Lung Institute, Imperial College, London UK

${ }^{6}$ Cardiac Surgery Department, Birmingham Children's Hospital NHS Foundation Trust,

Birmingham, UK

${ }^{7}$ Primary Care Department,

Queen Mary's University, London UK

${ }^{8}$ Department of Paediatrics, Northampton General Hospital NHS Trust, Northampton UK

\section{Correspondence to} Dr Katherine Brown, Cardiac Unit, Great Ormond Street Hospital NHS Foundation Trust, Great Ormond Street, London WC1N 3JH, UK; Katherine. Brown@gosh.nhs.uk

Received 19 April 2015 Revised 25 August 2015 Accepted 5 October 2015 Published Online First 29 January 2016

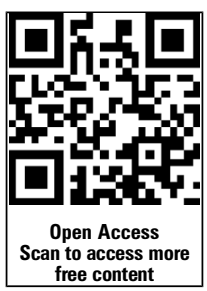

CrossMark

To cite: Tregay J, Wray J Crowe $\mathrm{S}$, et al. Arch Dis Child 2016:101:320-325.

\section{ABSTRACT}

Objective To qualitatively assess the discharge processes and postdischarge care in the community for infants discharged after congenital heart interventions in the first year of life.

Design Qualitative study using semistructured interviews and Framework Analysis.

Setting UK specialist cardiac centres and the services their patients are discharged to.

Subjects Twenty-five cardiologists and nurses from tertiary centres, 11 primary and secondary health professionals and 20 parents of children who had either died after discharge or had needed emergency

readmission.

Results Participants indicated that going home with an infant after cardiac intervention represents a major challenge for parents and professionals. Although there were reported examples of good care, difficulties are exacerbated by inconsistent pathways and potential loss of information between the multiple teams involved. Written documentation from tertiary centres frequently lacks crucial contact information and contains too many specialist terms. Non-tertiary professionals and parents may not hold the information required to respond appropriately when an infant deteriorates, this contributing to the stressful experience of managing these infants at home. Where they exist, the content of formal 'home monitoring pathways' varies nationally, and families can find this onerous.

Conclusions Service improvements are needed for infants going home after cardiac intervention in the UK, focusing especially on enhancing mechanisms for effective transfer of information outside the tertiary centre and processes to assist with monitoring and triage of vulnerable infants in the community by primary and secondary care professionals. At present there is no routine audit for this stage of the patient journey.

\section{BACKGROUND}

Over the past decade, early survival rates have improved for paediatric cardiac surgery (PCS) while contemporaneously children are being operated at a younger age and the proportion of patients with functionally single ventricle hearts and higher risk cardiac diagnoses have increased. ${ }^{1}$ Infants discharged home after PCS are a particularly vulnerable group: UK national audit data indicate that 3500-4000 procedures are undertaken annually in infants, ${ }^{2}$ and analysis indicates that $6.7 \%$ of infants 'successfully' discharged need emergency readmission to intensive care (paediatric

\section{What is already known on this topic}

- Infants who have had 'successful' cardiac surgery may deteriorate or die after discharge into the community.

- Some diagnostic groups are particularly precarious and there is some evidence that formal surveillance programmes may avert catastrophic deterioration.

- UK paediatric cardiac services increasingly work within 'congenital heart networks' incorporating paediatricians with expertise in cardiology.

\section{What this study adds}

- Discharge and follow-up pathways for infants going home following cardiac interventions are inconsistent and there is sometimes information loss between the multiple teams involved.

- Implementation of formal home monitoring pathways is variable between networks and between 'at risk' patient groups, and families may find these onerous to comply with.

- Written documentation from tertiary centres is often too jargon heavy to be useful to non-specialists and may not contain crucial contact information.

intensive care unit, PICU) or die outside the tertiary centre within a year, with complex babies facing considerably higher risks (Crowe S, Ridout D, Knowles R, et al. Development of a risk model for death or emergency readmission within one year following discharge from infant cardiac intervention and identification of patient risk groups for the purposes of service improvement. submitted for publication 2015). Conversely, those who survive beyond the first year are much less likely to die later in childhood. ${ }^{3}$

Healthcare service standards published by the UK Royal College of Nursing state that children and young people should only be treated in hospital when appropriate care cannot be provided in the community, and discharge should be planned once care can be provided at home. ${ }^{4}$ Tertiary paediatric cardiac centres and their linked secondary care 
providers (hospital-based teams) have been grouped and organised into 'congenital heart networks' in the UK, partly to improve postdischarge care and outreach services, ${ }^{5}$ Of note, it has been reported that increased surveillance at home for complex cardiac babies (known as home monitoring programmes (HMP)), which require cooperation between different sectors of the health service, may improve postdischarge outcomes; ${ }^{6-10}$ however, the extent of implementation of HMPs in the UK is unclear and other elements of the patient pathway after discharge may also warrant improvement.

As part of a wider 'Infant Heart Study', we aimed to capture and qualitatively analyse the views of professionals (across sectors of the health service and geographical regions) and of parents that had experienced difficult circumstances caring for an infant discharged after PCS, which could usefully inform future quality improvement efforts directed at the discharge process and postdischarge care of these patients.

\section{METHODS}

A specialist nurse based in each of the three participating centres identified parents whose child had undergone PCS in infancy and subsequently had an emergency readmission to a PICU or died outside the tertiary centre, and invited them to participate. We aimed to represent ethnic and social diversity in our sample and an interpreter was offered to families where English was not the spoken language. Parent interviews were conducted face-to-face by a single research fellow (JT) at the parental home, and lasted between 1 and $3 \mathrm{~h}$.

For tertiary health professional (HP) interviews, the research fellow (JT) specifically targeted those directly involved in infant cardiac follow-up. All cardiologists belonging to the British Congenital Cardiac Association (BCCA) were invited by email to participate. In centres where nobody volunteered, the research fellow contacted specific cardiologists until at least one was recruited from every UK centre. Tertiary nurses were nominated by the cardiologists or one another. Community nurses and health visitors were recruited through their links with a cardiac centre: this ensured that they had experience of providing support for at least one infant following PCS. Paediatricians, including those with special expertise in cardiology (PECs), and general practitioners (GPs) were approached via a study collaborator. We attempted to gain representation from both rural and urban communities. Interviews with $\mathrm{HPs}$ were conducted face-to-face or by telephone and lasted between 30 and $90 \mathrm{~min}$. Topic guides for these interviews included identification of 'high risk' patients; discharge planning; handover between tertiary and non-tertiary services; specialist centre follow-up; maintenance in the community, including details of any HMP; and systems for readmission if a child becomes unwell in the community.

Interviews were tape-recorded, transcribed verbatim and organised using Framework Analysis, ${ }^{11} 12$ a structured approach to managing and reducing bias in qualitative data. At least two members of the research team read and independently coded each transcript. An analysis group of JT, RK, JW, SC, CB and $\mathrm{KB}$ reviewed all the codes and grouped them under headings, which formed the basis for each thematic framework. Headings were agreed based on themes arising from the data and a wide range of a priori research questions related to different phases of the patient journey: these are summarised under the thematic headings in the Results section (example 'preparing for discharge'). JT entered data from each transcript into the frameworks. The analysis group used the completed frameworks to summarise the key themes across all interviewees.
The study had Research Ethics Committee approval and all interviewees provided informed consent.

\section{RESULTS}

\section{Descriptive information}

Participating families

Of 25 families contacted, 21 agreed to be interviewed but one was excluded, as they did not meet inclusion criteria. Fourteen interviews were conducted with the mother alone and six with both parents. The range of ethnic, educational, and socioeconomic backgrounds in the sample is shown in table 1. One parent did not speak English as a first language and two were bilingual. All children had their index surgery between September 2009 and October 2013. Postsurgery, 12 children were discharged home directly from the specialist centre, and 8 were discharged to their local hospital in a 'step-down' arrangement. Eleven families were bereaved.

\section{Health professionals}

A total of 36 HPs were interviewed; 25 were from the tertiary centres, and 11 were involved in the care of children after discharge from the tertiary centres (see table 2). One cardiologist was interviewed from each tertiary centre (12 surgical and 2 non-surgical centres).

Table 1 Family and child characteristics

\begin{tabular}{|c|c|}
\hline Demographic information & Number \\
\hline \multicolumn{2}{|l|}{ Ethnicity (of child) } \\
\hline \multicolumn{2}{|l|}{ White } \\
\hline British & 14 \\
\hline European & 1 \\
\hline \multicolumn{2}{|l|}{ Asian } \\
\hline Bangladeshi & 1 \\
\hline Pakistani & 1 \\
\hline Other & 1 \\
\hline \multicolumn{2}{|l|}{ Mixed } \\
\hline White/Black African & 1 \\
\hline White/Black Other & 1 \\
\hline \multicolumn{2}{|l|}{ Congenital heart diagnoses } \\
\hline Hypoplastic left heart syndrome (HLHS) & 5 \\
\hline Functionally single ventricle disease (not HLHS) & 7 \\
\hline Functionally single ventricle disease (not HLHS)* & 1 \\
\hline Transposition of the great arteries* & 3 \\
\hline Tetralogy of Fallot & 1 \\
\hline Anomalous left coronary artery from pulmonary artery (ALCAPA) & 1 \\
\hline Total anomalous pulmonary venous connection & 1 \\
\hline Ventricular septal defect (VSD)* & 1 \\
\hline \multicolumn{2}{|l|}{ Index surgery } \\
\hline Norwood Stage 1 procedure & 5 \\
\hline Systemic to pulmonary arterial shunt & 10 \\
\hline Arterial switch procedure & 2 \\
\hline ALCAPA repair & 1 \\
\hline Total anomalous pulmonary venous drainage repair & 1 \\
\hline Closure of VSD & 1 \\
\hline \multicolumn{2}{|l|}{ Educational history (primary caregiver) } \\
\hline Learning difficulty & 1 \\
\hline Primary/secondary school & 11 \\
\hline Graduate & 5 \\
\hline Postgraduate & 3 \\
\hline
\end{tabular}

Tregay J, et al. Arch Dis Child 2016;101:320-325. doi:10.1136/archdischild-2015-308827 
Table 2 Summary of health professionals interviewed

\begin{tabular}{lc}
\hline Health professionals interviewed & Number \\
\hline Tertiary centres & \\
Cardiologists & 14 \\
Specialist cardiac nurses* & 10 \\
$\quad$ Allied health professionals & 1 \\
Total & 25 \\
Non-tertiary & \\
Paediatricians with expertise in cardiology & 3 \\
General paediatricians & 2 \\
General practitioners & 2 \\
Health visitors & 2 \\
Community nurses & 2 \\
Total & 11 \\
\hline${ }^{*}$ For example, cardiac liaison nurses, nurse practitioners, etc.
\end{tabular}

${ }^{*}$ For example, cardiac liaison nurses, nurse practitioners, etc.

\section{Qualitative data from interviews}

Data are presented below in sections corresponding to the patient journey, with illustrative quotations. Each section comments first on the areas of concern that were raised by respondents, and then highlights aspects of service provision they perceived to be effective.

\section{Preparing for discharge}

At all specialist centres, parents receive information and training using a range of verbal and written materials, delivered by several types of HP (box 1). There was significant variability between centres, but even within centres, content and emphasis could vary from day to day or patient to patient, even between children with the same condition. Some specialist centres had developed bespoke leaflets 'in-house' while others used those

\section{Box 1 Quotes linked to the text on preparing for discharge}

Quotes linked to the text on preparing for discharge

"They're sometimes given so much stuff that it's just chucked in a bag and never got out." (Q031; general practitioner (GP)) "Everything was such a blur really....it was all very, very raw and difficult to understand." (FR01; parent)

"I often have concerns particularly if it's the woman who doesn't speak English, about what they are translating because you think 'I don't think you are getting everything I am saying to you'" (HP017; specialist nurse)

"I don't get any communication from [tertiary centre] at all.... Families get paperwork themselves. I'll read their paperwork when I go and see them. I don't get any directed to me." (Q025-Health visitor)

"It's not necessarily a 'one size fits all' amount of information. That's possibly where the discharge procedures can fall down... I also think information like that is quite difficult to give in one hit-it needs to be given more than once for people to really understand." (Q033; GP)

"Until you're actually doing it, it doesn't really mean anything to you." (FR09; parent)

"I'm not a medical expert, so I'd like to be told in layman's terms....it's nice to know the long word, but it's nice to know what it actually means." (FR07; parent) generated by charities including the 'British Heart Foundation' or 'Little Hearts Matter'. HPs from all sectors varied in their views about the quality of information and training given to families, noting difficulties in prioritising the information most crucial to an individual patient.

Families remarked that it could be 'a lot to take on board all at once', or 'overwhelming'. Although several HPs had used interpreters, both professionals and families noted the adverse impact of language barriers; interpreters were not always available and information transfer often seemed incomplete. Interestingly, non-tertiary HPs interviewed rarely knew what information or training families were given before discharge.

\section{Service provision perceived to be effective}

HPs from all sectors felt that information and training was best given in chunks when families had the time and energy to concentrate, that it should be patient-specific and that parents should have a chance to check questions later. Tertiary HPs noted that checklists used when a patient was entering a HMP offered the advantages of consistency in terms of practice between professionals (see below CLN0017). Both HPs and families valued hands-on training for parents taking responsibility for care involving medical technologies (sometimes called 'competencies'). Clear 'lay terms' were seen as beneficial by families, as was practical information about 'what to look out for'.

\section{Discharge process from the specialist centre}

Tertiary HPs reported difficulties in identifying the correct secondary and primary HPs to contact before a patient goes home, and with resultant confusion, missed opportunities for communication and wasted time (box 2). Tertiary and secondary HPs reported that communication worked better where clinical networks are well established. Specialist technical terminology and the absence of key basic information rendered discharge documents less useful to community professionals and indeed families with some noting discharge documents were delayed. Families were aware that crucial opportunities for information

\section{Box 2 Quotes linked to the text on discharge processes}

Quotes linked to the text on discharge process from the specialist centre

"Some units don't communicate very well. It may be that they're not in our network and they function differently." (Q030; general paediatrician)

"It would be nice if there was consistency, but the bottom line is we're dealing with 6 or 7 local health boards that will have different priorities and community services may not be a priority for that particular area....we have to adapt what we do according to where they are." (F005; cardiologist)

"They were hoping my local hospital would give me a paediatrician by the time we left, which didn't happen....they tried to get me an A\&E passport card....but unless you have a paediatrician it's hard for you to have that." (F04; parent) "The patient has gone home and I have no idea who this is. If this patient crashes they will come to my local hospital and we would have no information at all about this patient and we would be managing them." (Q027; paediatrician with expertise in cardiology)

"If they give the information to parents, well give it to us as well. Don't let us go in blind." (Q026; community nurse) 
handover were sometimes missed and that coordination of care after discharge could be unclear and could delay their accessing help when they needed it. Community teams noted their scarcity of resources and how rarely individual HPs see babies with congenital heart disease (CHD) in their practice.

\section{Service provision perceived to be effective}

Tertiary and secondary HPs felt that transition was more effective when the network for a specialist centre was clearly defined, and a paediatrician, particularly one with expertise in cardiology (PEC), coordinated postdischarge care. Various HPs expressed the view that 'step down care' achieved by discharging potentially precarious babies from the tertiary centre to their local hospital before going home helped make this transition safer and improved communication. Early contact with their particular GP was valued by families, even if the child seemed stable.

\section{Maintenance at home}

The default arrangements for follow-up and routine surveillance varied (box 3). Failures to share information undermined the confidence that some families had in local services and presented challenges to HPs responsible for patient care at home.

Professionals varied in their identification of patients as 'high risk', which incorporated the following patient characteristics: palliated or uncorrected heart defects, comorbidities and feeding difficulties as well as family characteristics of poor English, recent migration, cultural pressures and chaotic or difficult economic circumstances. The patient risk status was reported by HPs as impacting management, including eligibility for HMP and provision of 'open access' to paediatric wards.

Table 3 summarises the responses of interviewees asked about the current provision of HMPs at their centre, which suggest that there is considerable variation across the UK. Importantly, HPs and some families expressed concern over the pressure of

Box 3 Quotes linked to the text on maintenance at home

Quotes linked to the text on maintenance at home

"There was an element of me having to liaise between the different organisations in order for everybody to have the information, which didn't strike me as something I should be doing." (FR08; parent)

"I think life would be easier [if there were] national standards for the monitoring of babies....I do think it would be much easier if everybody did the same....it would make community nurses lives much easier because some of the community nurses I've spoken to they have patients from several different centres.....it is really confusing for people" (CLN 0017; cardiac liaison nurse)

"...I was more focussed on the paperwork than my baby. I couldn't see what else was going on because I was so worried about every drop of milk." (FB05: parent)

"If local services aren't familiar with CHD then they can miss the opportunity to intervene before that child crashes a day later." (E008; cardiologist)

"That's one of the more difficult things to get right I thinkwho to call and when." (D007; Cardiologist)

" $[\mathrm{CLN}]$ was the main point of contact really... she was like a lifeline. I don't know how we would have been [if they didn't have a CLN]. (FB03; parent) complying with the requirements of HMPs for multiple measurements and documentation.

When a baby becomes unwell, it may be challenging for the families to adequately articulate their concerns (discussed in more detail elsewhere ${ }^{13}$ ). Both families and HPs noted difficulties encountered by non-specialists as they triaged babies who presented to primary or secondary care. Lack of confidence about the need for specialist input meant that action could be either overzealous ('calling for everything') or initiated 'too late'.

\section{Service provision perceived to be effective}

Families valued the role of the cardiac liaison nurses (CLNs), who act to mitigate some of the difficulties described above with phone calls to/from parents and relevant HPs. PECs were reported by some as able to bridge some of the information gaps between tertiary and secondary care; however, this role is not universally available. 'Open access' to general paediatric wards for complex babies was viewed as beneficial by both parents and HPs. Standardised follow-up with explicit triggers for action (known as 'breach criteria') were viewed by some HPs as helpful (see table 3).

\section{Non-medical support}

Families may face practical difficulties after their baby's discharge (childcare, transport, financial), but unless there are safeguarding or significant psychological issues, psychosocial support is unlikely to be provided. Parents struggle with the demands of caring for their baby, including maintaining complex regimens of medication or measurements, with some reporting difficulties obtaining repeat prescriptions from their GP. The words 'fear' and 'scary' recurred when parents and HPs described their emotions dealing with a sick baby in the home.

In practice, opting out of the role of being an 'expert parent' may not be an option for parents.

One thing [tertiary centre] said is you will become the expert as a parent. I didn't believe that at the start but then the moment you start going into the community you realise you're telling people what to do, rather than them telling you. (FB04; Parent)

\section{Service provision perceived to be effective}

Although not universally available, non-medical support was obtained from individual HPs in primary and secondary care with particularly strong approval expressed in respect of support provided by tertiary CLNs. The potential of the internet as a means of keeping in touch with HPs or accessing specialist charity helplines were noted.

\section{DISCUSSION}

This study is a qualitative appraisal of discharge and postdischarge care for babies undergoing intervention for CHD within the UK. The data are informed by professionals from secondary, primary and community care and every UK specialist centre, and by families who had first-hand experience of 'testing the systems' - all had either lost a baby or their baby had needed emergency readmission to PICU.

The study has several limitations. The parents approached were already known to the specialist nurses assisting with recruitment, so potentially represent those with a good relationship to the local team. Despite our attempts to achieve ethnic diversity, three-quarters of our sample were 'White British' families. Professionals approached were purposively sampled, so may not be typical of all clinicians involved in the care of 
Table 3 Summary of interviewee's reports of home monitoring within individual tertiary centres

\begin{tabular}{|c|c|c|c|c|c|c|c|c|c|c|c|c|c|c|}
\hline \multirow[b]{2}{*}{$\begin{array}{l}\text { Tertiary } \\
\text { centre }\end{array}$} & \multirow[b]{2}{*}{$\begin{array}{l}\text { Formal } \\
\text { HMP? }\end{array}$} & \multirow[b]{2}{*}{$\begin{array}{l}\text { Eligibility for formal HMP or } \\
\text { closer monitoring at home }\end{array}$} & \multicolumn{3}{|c|}{ Routine measurements } & \multicolumn{3}{|c|}{ Measurements taken by } & \multicolumn{3}{|c|}{ Breach criteria } & \multicolumn{3}{|c|}{ Specialist centre monitoring } \\
\hline & & & Frequency & Saturations & Weight & Parent & $\begin{array}{l}\text { Health } \\
\text { visitor }\end{array}$ & $\begin{array}{l}\text { Community } \\
\text { nurse }\end{array}$ & None & Standard & Individualised & $\begin{array}{l}\text { Regular calls } \\
\text { from CNS }\end{array}$ & $\begin{array}{l}\text { Parents call } \\
\text { CNS }\end{array}$ & $\begin{array}{l}\text { High-risk } \\
\text { clinic }\end{array}$ \\
\hline Centre A & $\checkmark$ & Single ventricle & Daily & $\checkmark$ & $\checkmark$ & $\checkmark$ & $\checkmark$ & & & $\checkmark$ & & $\checkmark$ & & $\checkmark$ \\
\hline Centre B & $x$ & Single ventricle & Weekly & $\checkmark$ & $\checkmark$ & & $\checkmark$ & $\checkmark$ & $\checkmark$ & & & & $\checkmark$ & \\
\hline Centre C & $\checkmark$ & Single ventricle+shunts & Weekly & $\checkmark$ & $\checkmark$ & & $\checkmark$ & $\checkmark$ & & $\checkmark$ & & $\checkmark$ & & \\
\hline Centre D & $\checkmark$ & Single ventricle, but flexible & Weekly & $\checkmark$ & & $\checkmark$ & & & & $\checkmark$ & & $\checkmark$ & & $\checkmark$ \\
\hline Centre $\mathrm{E}$ & $x$ & Single ventricle+shunts & Daily & $\checkmark$ & & $\checkmark$ & & & $\checkmark$ & & & $\checkmark$ & & \\
\hline Centre F & $\checkmark$ & Single ventricle+shunts & Daily & $\checkmark$ & $\checkmark$ & $\checkmark$ & & & & $\checkmark$ & & & $\checkmark$ & \\
\hline Centre G & $\checkmark$ & HLHS only & Weekly & $\checkmark$ & $\checkmark$ & & $\checkmark$ & $\checkmark$ & & $\checkmark$ & & $\checkmark$ & $\checkmark$ & \\
\hline Centre $\mathrm{H}$ & $x$ & Single ventricle+shunt dependent & Weekly & $\checkmark$ & $\checkmark$ & & $\checkmark$ & $\checkmark$ & $\checkmark$ & & & $\checkmark$ & & \\
\hline Centre I & $\checkmark$ & HLHS only & Daily & $\checkmark$ & $\checkmark$ & $\checkmark$ & & & & $\checkmark$ & & $\checkmark$ & & \\
\hline Centre J & $x$ & All shunt-dependent & Weekly & $\checkmark$ & & & & $\checkmark$ & $\checkmark$ & & & $\checkmark$ & & $\checkmark$ \\
\hline Centre K & $\checkmark$ & Single ventricle+shunts & $\begin{array}{l}\text { Twice } \\
\text { weekly }\end{array}$ & $\checkmark$ & $\checkmark$ & & $\checkmark$ & $\checkmark$ & & $\checkmark$ & & & $\checkmark$ & \\
\hline Centre L & $\checkmark$ & Single ventricle & $\begin{array}{l}\text { Twice } \\
\text { weekly }\end{array}$ & $\checkmark$ & $\checkmark$ & & $\checkmark$ & $\checkmark$ & & & $\checkmark$ & $\checkmark$ & $\checkmark$ & \\
\hline Centre M & $\checkmark$ & HLHS only & 1-2/week & $\checkmark$ & $\checkmark$ & & $\checkmark$ & $\checkmark$ & & $\checkmark$ & & $\checkmark$ & & \\
\hline Centre N & $x$ & HLHS only & Weekly & $\checkmark$ & $\checkmark$ & & $\checkmark$ & $\checkmark$ & $\checkmark$ & & & $\checkmark$ & & \\
\hline Centre 0 & $x$ & Follow protocol of surgical centres & & & & & & & & & & $\checkmark$ & & \\
\hline Centre $\mathrm{P}$ & $x$ & Clinical judgement & Weekly & $\checkmark$ & $\checkmark$ & & $\checkmark$ & $\checkmark$ & $\checkmark$ & & & $\checkmark$ & & \\
\hline
\end{tabular}

CNS, clinical nurse specialist; HLHS, hypoplastic left heart syndrome; HMP, home monitoring programmes; shunt, systemic-to-pulmonary arterial shunt; single ventricle, functionally single ventricle. 
cardiac infants, and furthermore we were limited to one or two per centre. Though we interviewed professionals from secondary and primary care and from rural and urban settings, given the small number of subjects and the large extent of the services they represent, we may not have captured a complete range of views.

Our study demonstrates certain 'system problems' within the discharge and follow-up pathways for infants going home following cardiac interventions:

Paediatric cardiac network services incorporate multiple team interfaces with corresponding steep knowledge gradients and opportunities for information loss. Infants with CHD may be medically fragile and subject to dangerous deterioration; many non-specialist HPs and parents find this responsibility challenging and extremely stressful. The pressures resulting from the system problems our study identified fall particularly on parents, CLNs and paediatricians with expertise in cardiology (PECs).

There is some evidence that HMPs for infants with complex single ventricle conditions are beneficial, ${ }^{6-10}$ but our study suggests that implementation in the UK is variable and the complex regimens of feeding, medications, weights and saturation monitoring with 'breach criteria' place considerable burden on those responsible for them.

In practice, infants with heart disease who become acutely unwell at home are likely to present to either a GP or a local hospital via $\mathrm{A}+\mathrm{E}$ or through 'open access' to the paediatric department. Our study identified problems with correct identification of the deteriorating child and difficulties determining what appropriate steps to take from the perspective of both primary and secondary HPs. Within this context, interview participants reported the potential benefit to both parents and secondary HPs of local 'step-down' care before an infant's final discharge home after cardiac surgery, such that the child is known when in a stable condition. Our findings also highlighted the effective role that named and informed PECs with responsibility for local children with heart disease could play in strengthening networks. PECs have the appropriate competence to consider the baby's cardiac and other medical problems as a 'whole'; however, they may not be the first point of contact for the deteriorating infant with CHD, and there may be potential for learning from related secondary care examples such as scoring tools that have been deployed in $\mathrm{A}+\mathrm{E}$ and used by nonspecialist HPs to detect signs of deterioration in presenting children. ${ }^{14}$

Finally, at present, the focus of national and international audit remains on 30-day mortality rates for PCS, ${ }^{2} 1516$ and we note that additional audit metrics focusing on the post discharge stage of the patient journey may be a useful lever for quality improvement in the future.

Acknowledgements We would like to thank Nurse Specialists Helen Silk, Liz Smith, Christie Fox and Kay Dyer for their assistance with recruitment of parents to the study. We would also like to thank all of the parents and health professionals who kindly agreed to be interviewed for the study. Dr Daubeney is supported by the Biomedical Research Unit at the Royal Brompton Hospital and Dr Crowe is supported by the Health Foundation.
Contributors JT conducted the interviews. JW, SC, RK, CB and KB reviewed the transcripts and structured the Framework analysis. All authors contributed to the multidisciplinary reviews of the Framework content and reviewed the manuscript

Funding This project was funded by the National Institute for Health Research Health Services and Delivery Research programme (Project No: 10/2002/29).

Disclaimer The views and opinions expressed therein are those of the authors, and do not necessarily reflect those of the NIHR HS and DR programme or the Department of Health.

Competing interests None declared.

Ethics approval NRES Committee London-Central (12/L0/1398).

Provenance and peer review Not commissioned; externally peer reviewed.

Open Access This is an Open Access article distributed in accordance with the Creative Commons Attribution Non Commercial (CC BY-NC 4.0) license, which permits others to distribute, remix, adapt, build upon this work non-commercially, and license their derivative works on different terms, provided the original work is properly cited and the use is non-commercial. See: http://creativecommons.org/ licenses/by-nc/4.0/

\section{REFERENCES}

1 Brown $\mathrm{KL}$, Crowe $\mathrm{S}$, Franklin $\mathrm{R}$, et al. Trends in 30-day mortality rate and case mix for paediatric cardiac surgery in the UK between 2000 and 2010. Open Heart 2015;2:e000157.

2 NICOR. NICOR: National Institute for Cardiovascular Outcomes Research: Congenital Heart Diseases Website. University College London; 2015. http://www.nicor4.nicor. org.uk/CHD (accessed Jan 2015).

3 Billett J, Majeed A, Gatzoulis M, et al. Trends in hospital admissions, in-hospital case fatality and population mortality from congenital heart disease in England, 1994 to 2004. Heart 2008;94:342-8.

4 Nursing RCo. Health care service standards in caring for neonates, children and young people. London: RCN, 2011.

5 Qureshi SA. Requirements for provision of outreach paediatric cardiology service. London, UK: BCCA, 2009.

6 Ghanayem NS, Cava JR, Jaquiss RD, et al. Home monitoring of infants after stage one palliation for hypoplastic left heart syndrome. Semin Thorac Cardiovasc Surg Pediatr Card Surg Annu 2004;7:32-8

7 Petit CJ, Fraser CD, Mattamal R, et al. The impact of a dedicated single-ventricle home-monitoring program on interstage somatic growth, interstage attrition, and 1-year survival. J Thorac Cardiovasc Surg 2011:142:1358-66.

8 Dobrolet NC, Nieves JA, Welch EM, et al. New approach to interstage care for palliated high-risk patients with congenital heart disease. J Thorac Cardiovasc Surg 2011;142:855-60.

9 Srinivasan C, Sachdeva R, Morrow WR, et al. Standardized management improves outcomes after the Norwood procedure. Congenit Heart Dis 2009:4:329-37.

10 Hansen JH, Furck AK, Petko C, et al. Use of surveillance criteria reduces interstage mortality after the Norwood operation for hypoplastic left heart syndrome. Eur J Cardiothorac Surg 2012;41:1013-18.

11 Srivastava AaT SB. Framework Analysis: a qualitative methodology for applied policy research. JOAAG 2009:4:72-9.

12 Gale NK, Heath G, Cameron E, et al. Using the framework method for the analysis of qualitative data in multi-disciplinary health research. BMC Med Res Methodol 2013;13:117.

13 Tregay J, Brown KL, Knowles R, et al. Signs of deterioration in infants discharged home following congenital heart surgery in the first year of life: a qualitative study. Arch Dis Child 2015. In press. doi:10.1136/archdischild-2014-308092

14 Bradman K, Borland M, Pascoe E. Predicting patient disposition in a paediatric emergency department. J Paediatr Child Health 2014;50:E39-44.

15 Jacobs JP, O'Brien SM, Pasquali SK, et al. Variation in outcomes for risk-stratified pediatric cardiac surgical operations: an analysis of the STS Congenital Heart Surgery Database. Ann Thorac Surg 2012;94:564-71; discussion 71-2.

16 EACTS. EACTS congenital database gold standards. In: Surgery EAfC, ed. Congenital database gold standard reports. Warsaw Poland: Children's Memorial Health Institute, 2013. http://www.eactscongenitaldb.org/index.php? LANG=en\&level=2\&struct=14_1 